for

4

\title{
Face-Specific Occlusion of Lipid Vesicles within Calcium Oxalate
}

Monohydrate

\author{
Jialin Chi, ${ }^{1}$ Wenjun Zhang, ${ }^{1}$ Christine V. Putnis, ${ }^{2,3}$ and Lijun Wang*,1 \\ ${ }^{1}$ College of Resources and Environment, Huazhong Agricultural University, Wuhan 430070, \\ China
}

${ }^{2}$ Institut für Mineralogie, University of Münster, 48149 Münster, Germany

${ }^{3}$ School of Molecular and Life Science, Curtin University, 6845 Perth, Australia

SI Tables (1-3)

SI Figures (1-10)

\section{SI References}

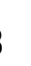 9}


Table S1. Solution conditions for all the AFM experiments.

\begin{tabular}{|c|c|c|c|c|c|}
\hline \multirow{2}{*}{ Experiments } & \multicolumn{3}{|c|}{ Concentration (mM) } & \multirow{2}{*}{$I S$} & \multirow{2}{*}{ pH } \\
\hline & $\mathrm{CaCl}_{2}$ & $\mathrm{~K}_{2} \mathrm{C}_{2} \mathrm{O}_{4}$ & Vesicle & & \\
\hline Adsorption & 0.27 & 0.27 & 2.5 & 0.15 & 7 \\
\hline \multirow[t]{2}{*}{ Occlusion } & 0.365 & 0.365 & 0 & 0.15 & 7 \\
\hline & 0.27 & 0 & 20 & 0.15 & 5 \\
\hline \multirow{3}{*}{$\begin{array}{c}\text { Tip } \\
\text { modification }\end{array}$} & 0.27 & 0 & 20 & 0.15 & 7 \\
\hline & 0.27 & 0 & 20 & 0.15 & 9 \\
\hline & 0.27 & 0.27 & 0 & 0.15 & 5 \\
\hline \multirow[t]{2}{*}{ DFS } & 0.27 & 0.27 & 0 & 0.15 & 7 \\
\hline & 0.27 & 0.27 & 0 & 0.15 & 9 \\
\hline
\end{tabular}


Table S2. Raman shift $\left(\mathrm{cm}^{-1}\right)$ of COM and vesicles.

\begin{tabular}{cccc}
\hline Composition & Wavenumber $\left(\mathbf{c m}^{-1}\right)$ & Assignments & References \\
\hline COM & 1462,1490 & $\mathrm{v}_{\mathrm{a}}(\mathrm{C}=\mathrm{O}), \mathrm{v}_{\mathrm{s}}(\mathrm{C}-\mathrm{O})$ & Chiu et al., 2010 \\
Vesicle & $1440-1450$ & $\beta(\mathrm{C}-\mathrm{H})$ & Bush et al., 1980; \\
& $2800-2900$ & $v_{\mathrm{s}}\left(\mathrm{CH}_{2}\right), v_{\mathrm{as}}\left(\mathrm{CH}_{2}\right)$ & Li et al., 2017 \\
\hline
\end{tabular}

35

36 
Table S3. The corresponding fitting parameters from DFS data.

\begin{tabular}{|c|c|c|c|c|c|}
\hline Vesicles & Face & $\mathbf{p H}$ & $f_{e q}(p N)$ & $\mathbf{x}_{\mathbf{t}}(\AA)$ & $-\Delta G_{b}(k J / m o l)$ \\
\hline \multirow{6}{*}{$\mathrm{PC}$} & \multirow{3}{*}{$(\overline{1} 01)$} & 5 & $256.60 \pm 3.00$ & $0.88 \pm 0.05$ & $22.50 \pm 1.99$ \\
\hline & & 7 & $273.55 \pm 6.91$ & $0.98 \pm 0.02$ & $26.79 \pm 0.14$ \\
\hline & & 9 & $286.26 \pm 14.39$ & $0.95 \pm 0.02$ & $27.05 \pm 1.42$ \\
\hline & \multirow{3}{*}{$(010)$} & 5 & $122.51 \pm 10.96$ & $0.91 \pm 0.08$ & $11.17 \pm 0.15$ \\
\hline & & 7 & $111.06 \pm 8.26$ & $0.93 \pm 0.02$ & $10.42 \pm 0.97$ \\
\hline & & 9 & $111.92 \pm 15.01$ & $0.82 \pm 0.03$ & $9.19 \pm 1.14$ \\
\hline \multirow{6}{*}{ DOTAP } & \multirow{3}{*}{$(\overline{1} 01)$} & 5 & $93.19 \pm 7.70$ & $0.91 \pm 0.03$ & $8.49 \pm 0.76$ \\
\hline & & 7 & $87.10 \pm 3.64$ & $0.92 \pm 0.03$ & $8.01 \pm 0.45$ \\
\hline & & 9 & $85.72 \pm 4.05$ & $0.89 \pm 0.01$ & $7.71 \pm 0.37$ \\
\hline & \multirow{3}{*}{$(010)$} & 5 & $325.43 \pm 14.28$ & $0.93 \pm 0.07$ & $30.13 \pm 1.29$ \\
\hline & & 7 & $306.87 \pm 10.35$ & $0.92 \pm 0.02$ & $28.52 \pm 0.69$ \\
\hline & & 9 & $272.05 \pm 10.69$ & $0.88 \pm 0.05$ & $24.11 \pm 2.10$ \\
\hline \multirow{6}{*}{ DPPC } & \multirow{3}{*}{$(\overline{1} 01)$} & 5 & $89.51 \pm 4.98$ & $0.82 \pm 0.03$ & $7.40 \pm 0.67$ \\
\hline & & 7 & $99.10 \pm 6.01$ & $0.82 \pm 0.04$ & $8.17 \pm 0.51$ \\
\hline & & 9 & $109.22 \pm 8.18$ & $0.83 \pm 0.04$ & $9.08 \pm 0.80$ \\
\hline & \multirow{3}{*}{$(010)$} & 5 & $108.48 \pm 3.63$ & $0.83 \pm 0.02$ & $9.02 \pm 0.47$ \\
\hline & & 7 & $99.17 \pm 4.34$ & $0.82 \pm 0.03$ & $8.21 \pm 0.53$ \\
\hline & & 9 & $94.99 \pm 4.44$ & $0.80 \pm 0.06$ & $7.61 \pm 0.34$ \\
\hline
\end{tabular}



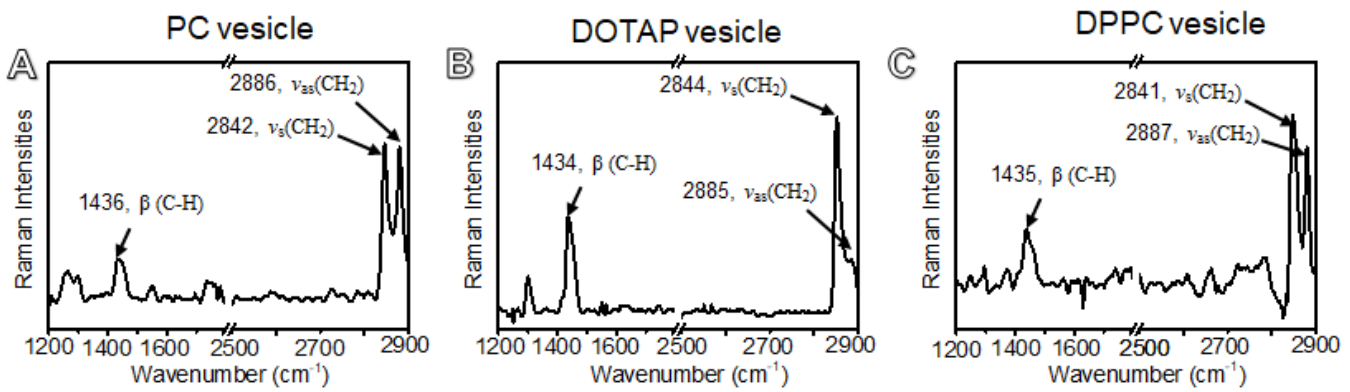

Figure S1. Raman spectra of the different vesicles. The Raman peaks of the $\beta(\mathrm{C}-\mathrm{H})$ are located in the $1440-1450 \mathrm{~cm}^{-1}, v_{\mathrm{s}}\left(\mathrm{CH}_{2}\right)$ and $v_{\text {as }}\left(\mathrm{CH}_{2}\right)$ range from 2800 to 2900 $\mathrm{cm}^{-1}$.
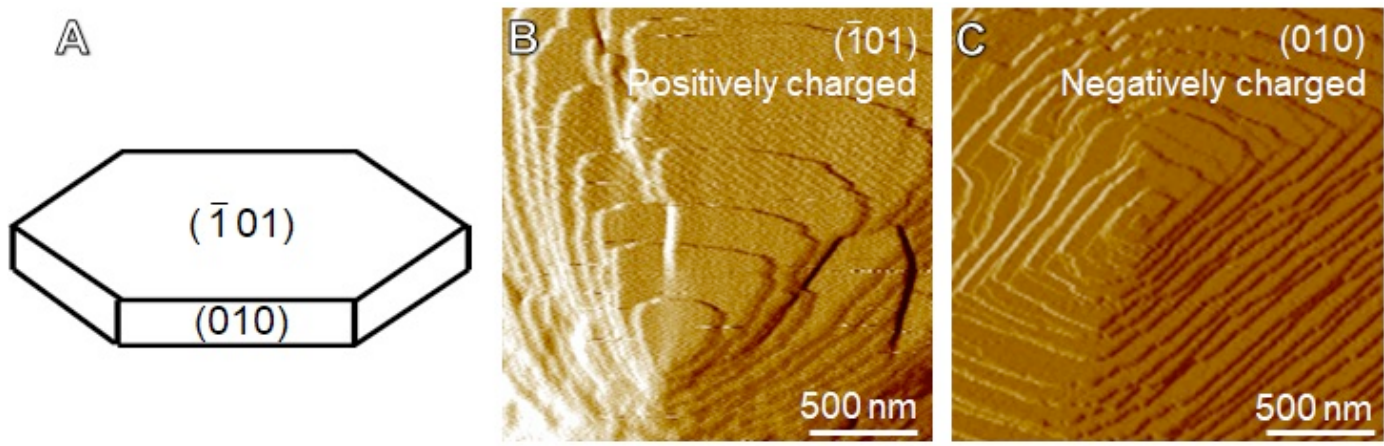

Figure S2. (A) The hexagonal COM crystals contain two typical (101) and (010)

57 faces. (B) Triangular-shaped growth hillocks on the ( $\overline{1} 01)$ faces and (C)

58 rectangular-shaped hillocks on the (010) face observed by AFM. 

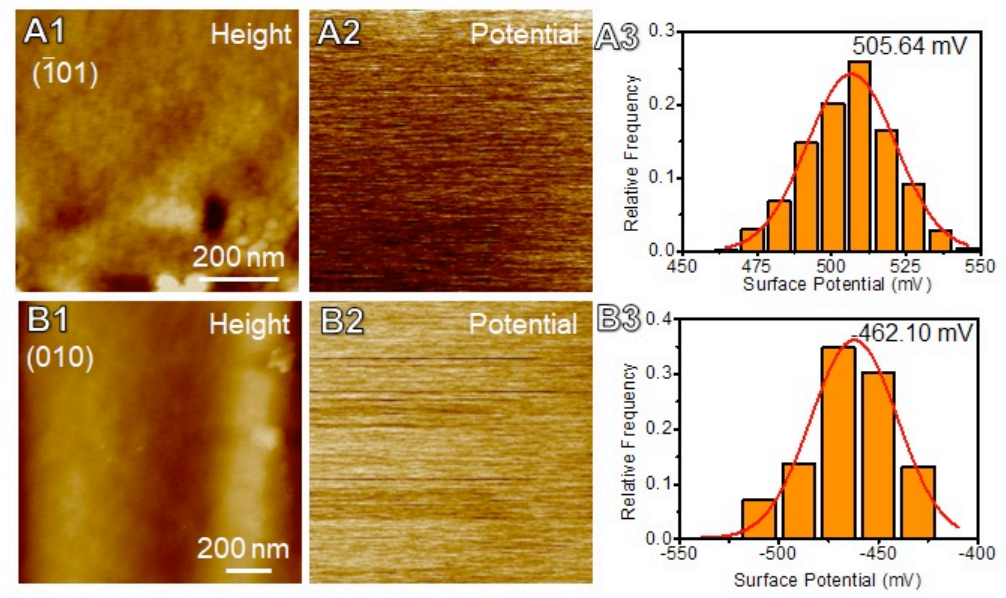

Figure S3. The surface potentials of the (A1-A3) (101) and (B1-B3) (010) faces. The

61 (101) face is positively charged $(505.64 \pm 1.17 \mathrm{mV})$, while the $(010)$ face is 62 negatively charged $(-462.10 \pm 1.92 \mathrm{mV})$.
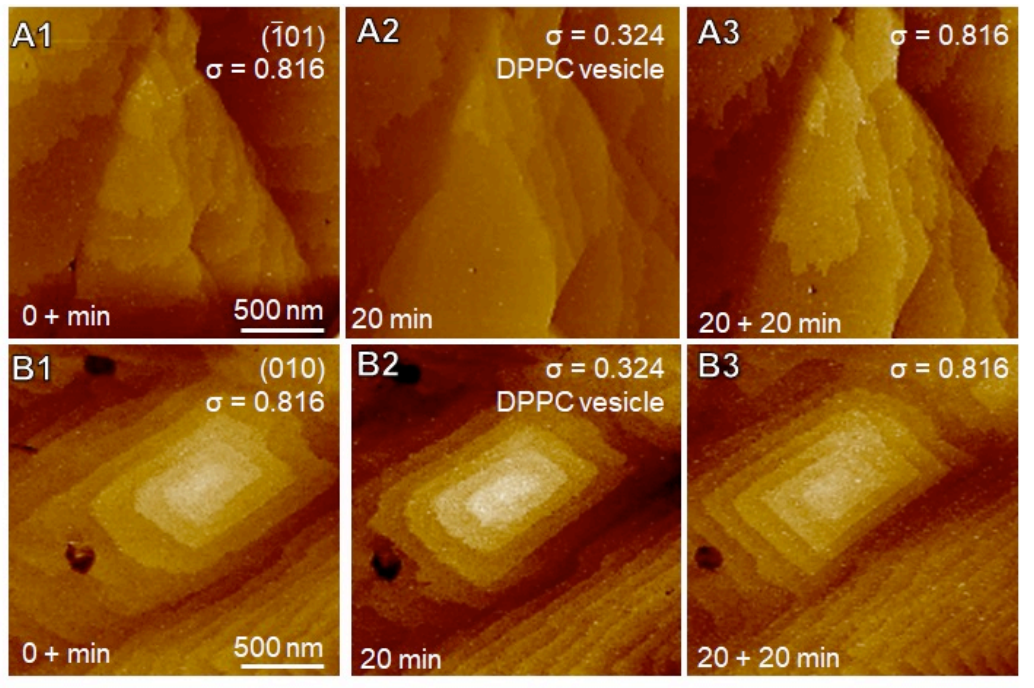

Figure S4. No DPPC vesicles were adsorbed nor incorporated on both the (101) and 65 (010) faces. 

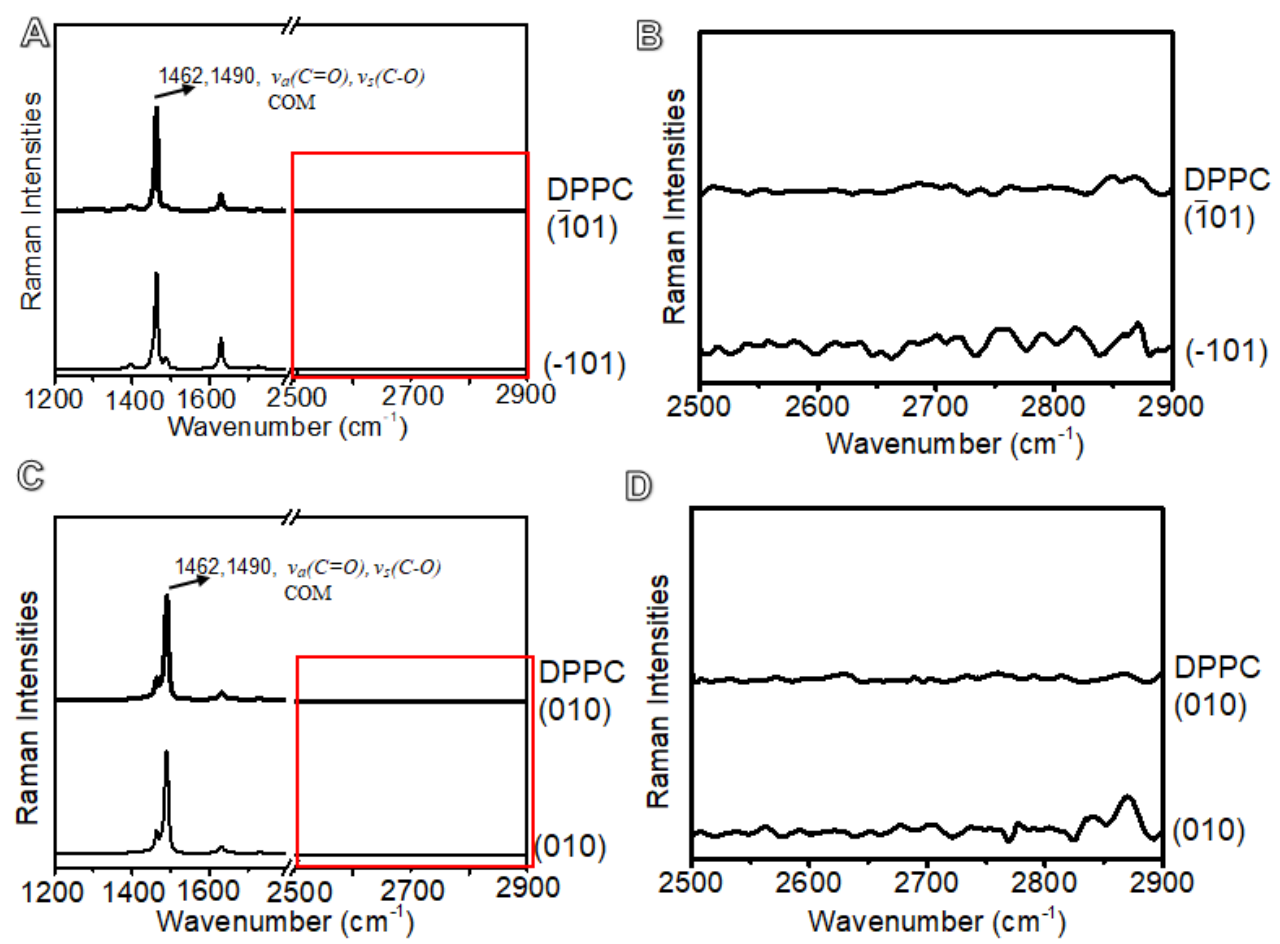

Figure S5. (A) Raman spectra of the DPPC vesicles on COM surfaces. No vesicle signals were detected by Raman spectra. (B, D) Enlargement of red squares in (A and C). 

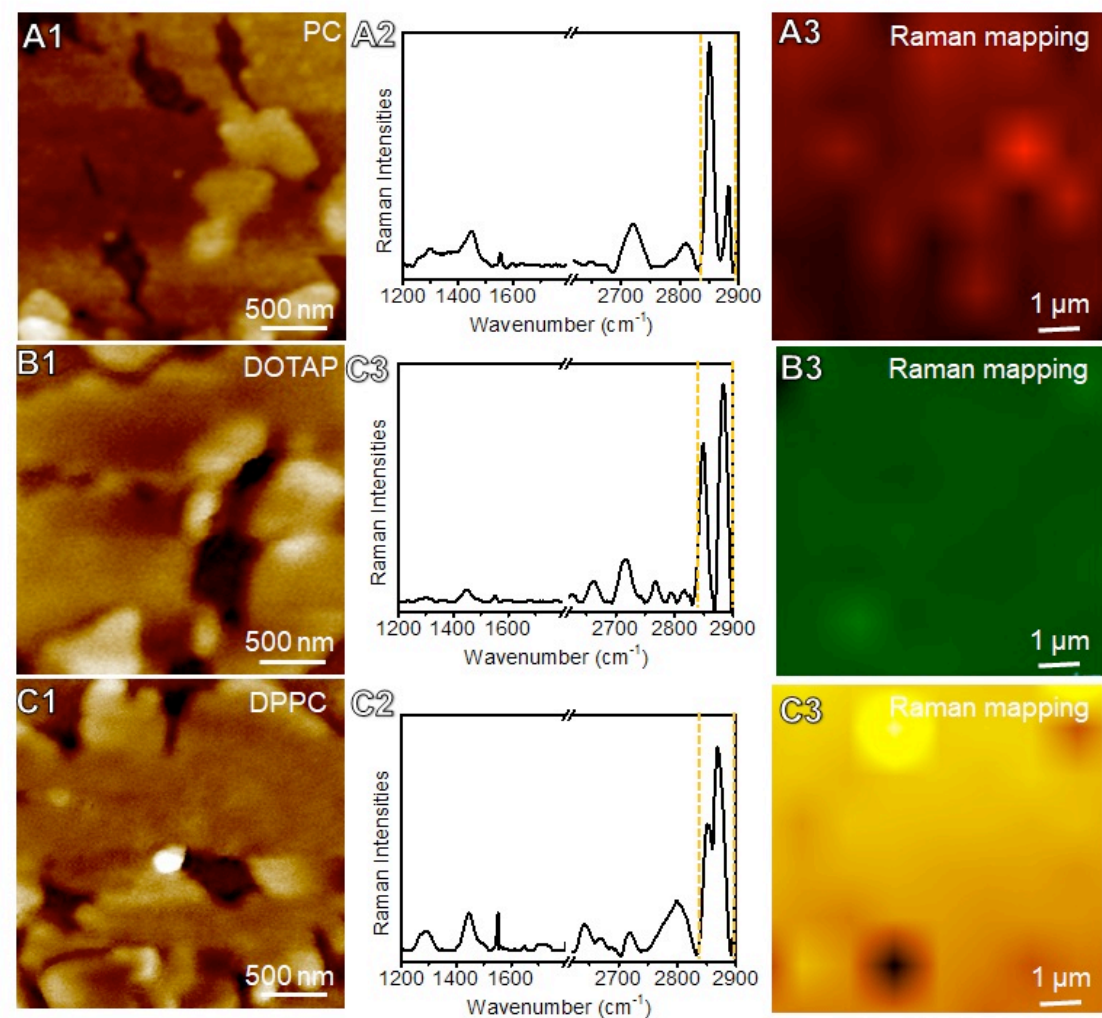

Figure S6. AFM and Raman spectra of the vesicle-formed membranes on the silicon

81 slides.

82 


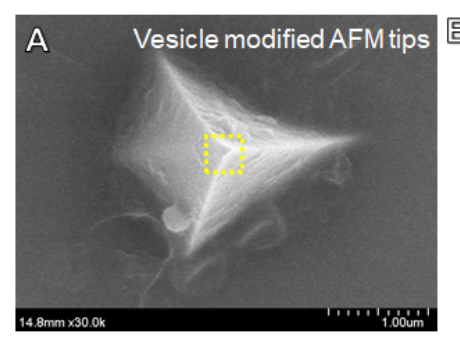

D

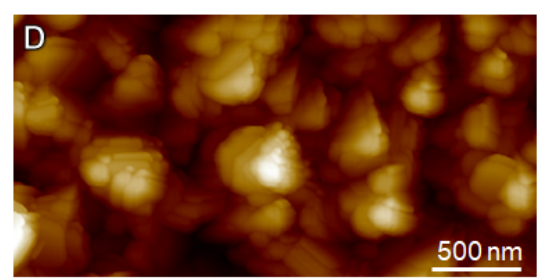

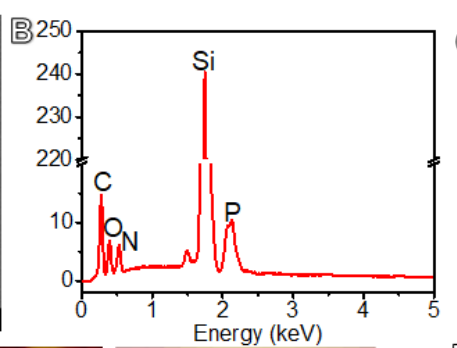

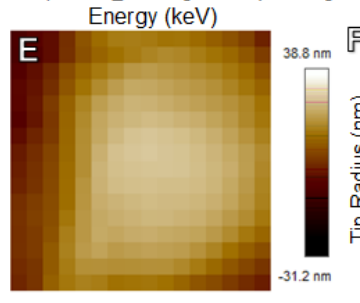

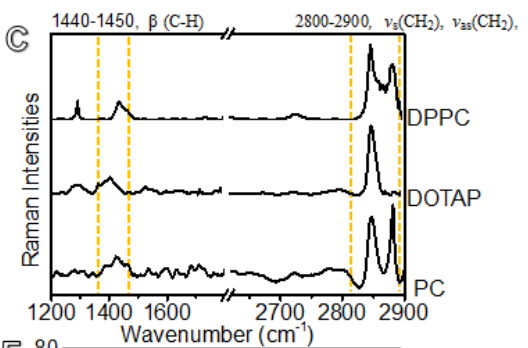

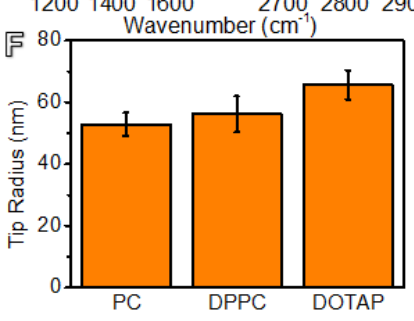

Figure S7. (A) SEM image and (B) corresponding EDS spectra show the peaks of C,

$\mathrm{O}, \mathrm{N}, \mathrm{P}$ and Si elements, indicating that the membrane distributed uniformly on the tips. (C) Raman spectra of the modified tips also showed the peaks of $\beta(\mathrm{C}-\mathrm{H})$ located in 1440-1450 cm $\mathrm{cm}^{-1}$, and $v_{\mathrm{s}}\left(\mathrm{CH}_{2}\right)$ and $v_{\text {as }}\left(\mathrm{CH}_{2}\right)$ located in 2800 to $2900 \mathrm{~cm}^{-1}$. (D-F) The

91 corrected tip radius by AFM. The tip radius modified with PC, DPPC and DOTAP

$92 \quad$ were $52.9 \pm 3.8 \mathrm{~nm}, 56.2 \pm 5.8 \mathrm{~nm}$ and $65.6 \pm 4.7 \mathrm{~nm}$, respectively. 

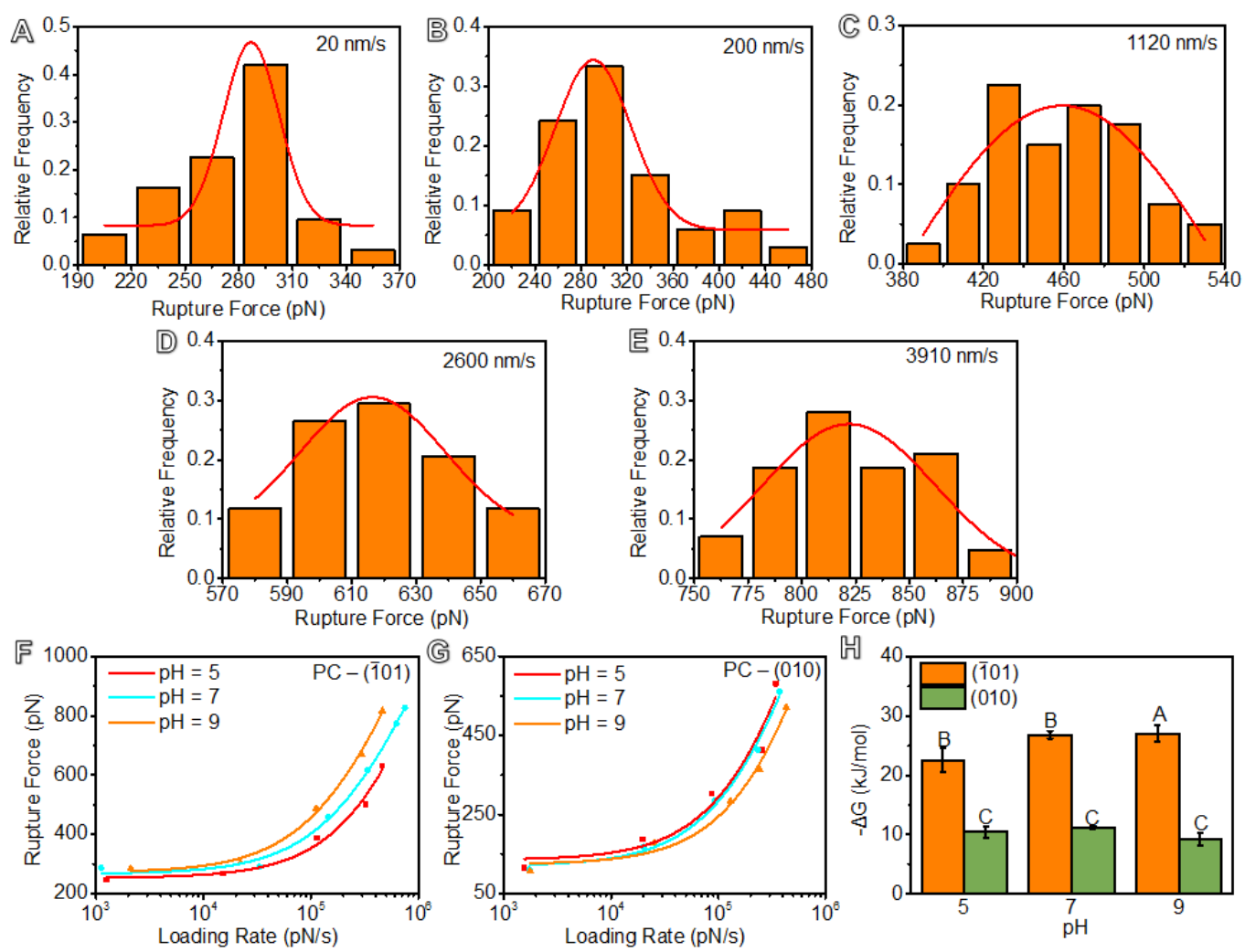

Figure S8. (A-E) The rupture forces between the PC lipid and the (101) face at $\mathrm{pH}=$ 7.0 at different loading rates ranging from $20-3910 \mathrm{~nm} / \mathrm{s}$. (F-G) DFS of PC binding to the (101) (F) and (010) faces at different $\mathrm{pH}$ values. $(\mathrm{H})$ The binding free energy between the PC and crystal faces at different $\mathrm{pH}$ values. Different uppercase symbols indicate significant differences at $P<0.01$. 

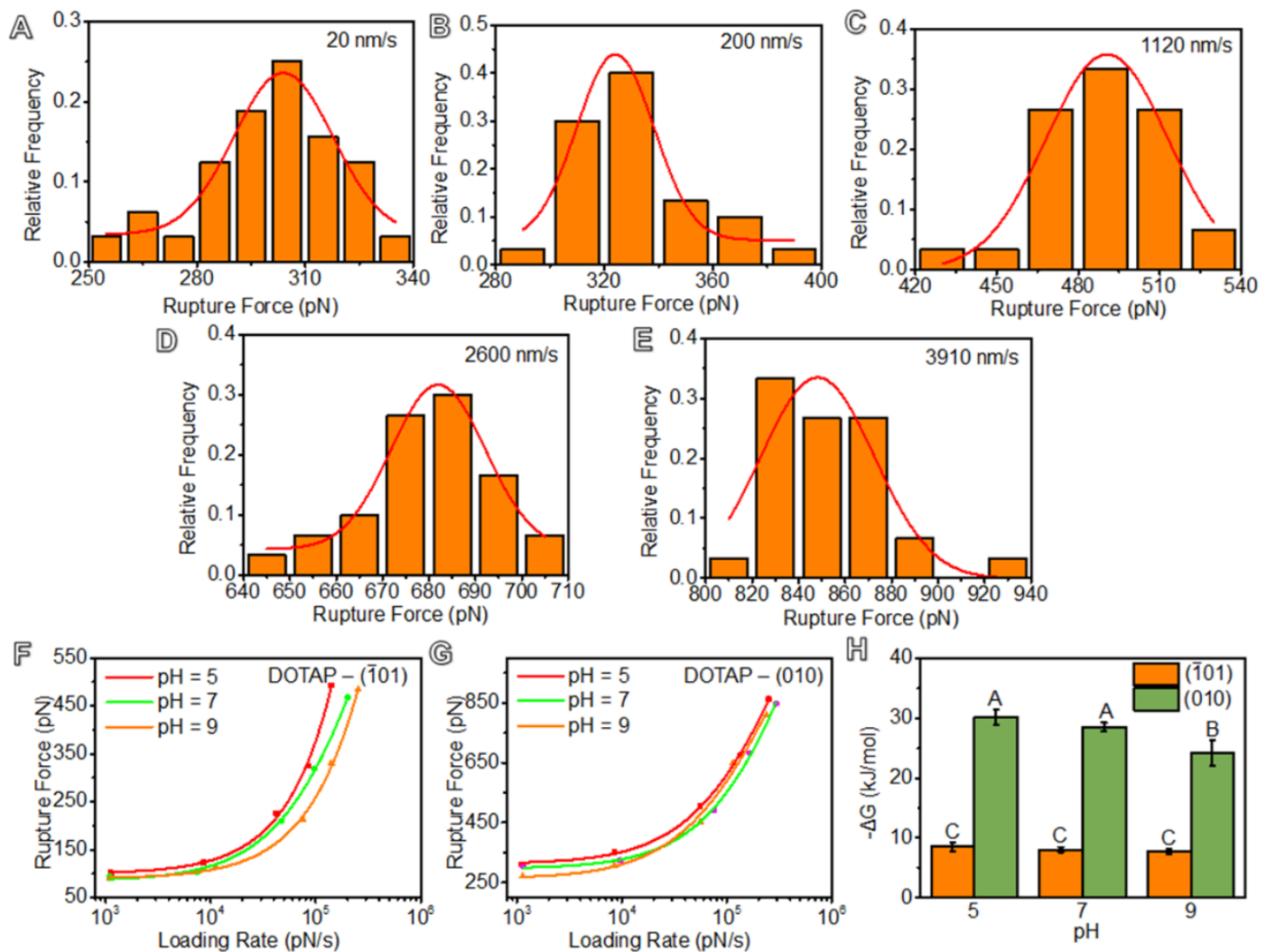

Figure S9. (A-E) The rupture forces of DOTAP lipid and the (010) face at $\mathrm{pH}=7.0$.

(F-G) DFS of DOTAP binding to the (101) (F) and (010) $(\mathrm{G})$ faces at different $\mathrm{pH}$ values. $(\mathrm{H})$ The binding free energy between the DOTAP and crystal faces at different $\mathrm{pH}$ values. Different uppercase symbols indicate significant differences at $P<0.01$. 

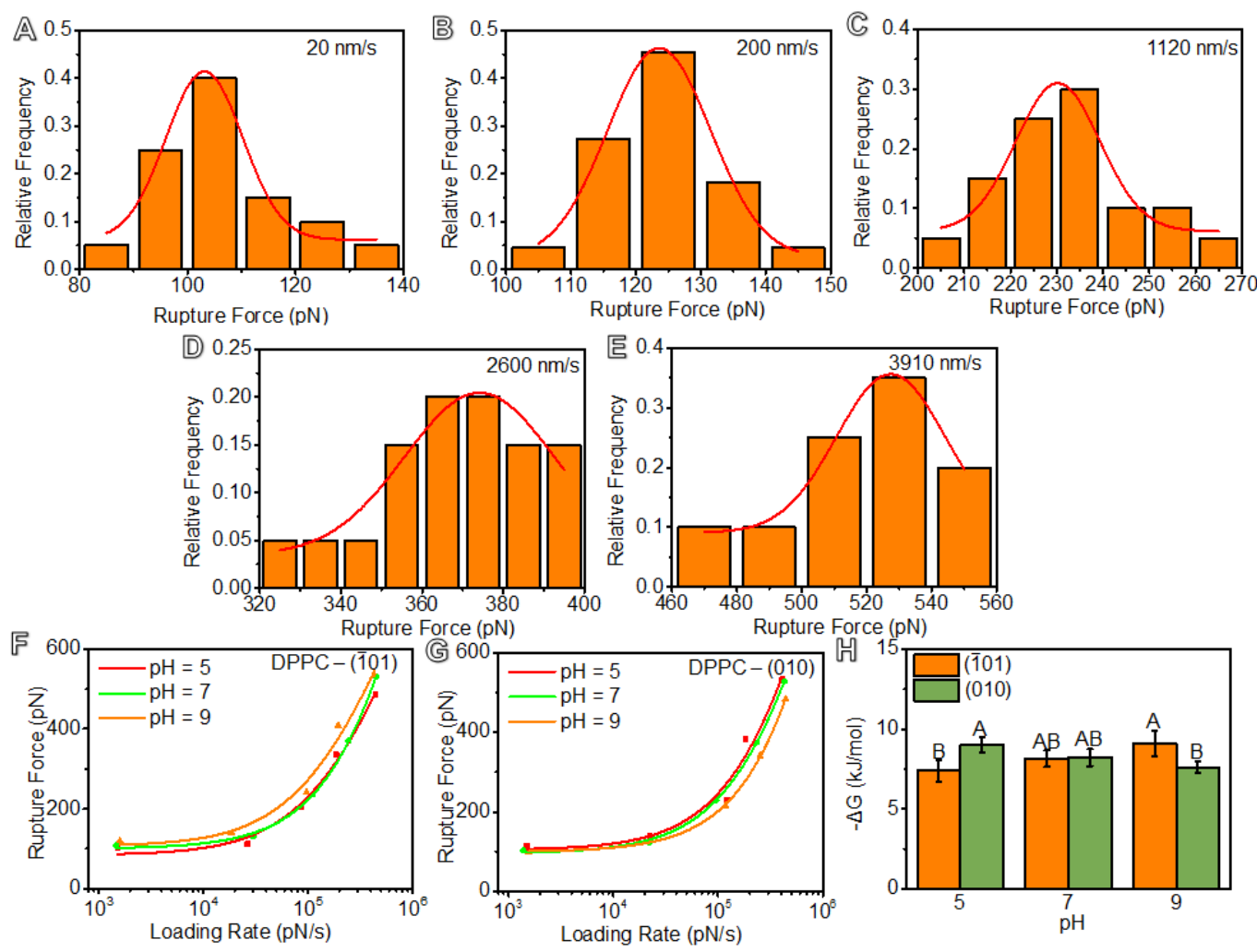

Figure S10. (A-E) The rupture forces of DPPC lipid and the (010) face at $\mathrm{pH}=7.0$.

(F-G) DFS of DPPC binding to the $(101)(F)$ and $(010)(G)$ faces at different $\mathrm{pH}$ values. $(\mathrm{H})$ The binding free energy between the DPPC and crystal faces at different $\mathrm{pH}$ values. Different uppercase symbols indicate significant differences at $P<0.01$.

\section{SI References}

1. Chiu, Y. C., Yang, H. Y., Lu, S. H., Chiang, H. K. Micro-Raman spectroscopy identification of urinary stone composition from ureteroscopic lithotripsy urine powder. J. Raman Spectrosc. 2010, 41, 136-141. 
115 systems: effect of hydration and sterol addition on Raman spectra of dipalmitoyl 116 phosphatidylcholine multilayers. Biochemistry 1980, 19, 4429-4436.

117 3. Li, M.; Wang, L. J.; Putnis, C. V. Energetic basis for inhibition of calcium 118 phosphate biomineralization by osteopontin. J. Phys. Chem. B 2017, 121, 24, $119 \quad 5968-5976$. 